\title{
LA TRATADÍSTICA NOBILIARIA COMO ESPEJO DE NOBLES. EL EJEMPLO DE JUAN BENITO GUARDIOLA Y SU TRATADO DE NOBLEZA DE 1591.
}

\author{
José Antonio Guillén Berrendero \\ Universidad Complutense de Madrid
}

A la memoria de mi padre.

"La nobleza todos la aman, desean y procuran, tapa y encubre muchos defectos, tiene animo para no huir, generosidad para dar crianza en el hablar, corazón para husar más clemencia para perdonar, acrecienta la libertad, estimada, temida y acatada de gran claridad y resplandor." ${ }^{2}$

En los albores del siglo XVII los nobles, portadores de una firme herencia cultural, se ven obligados a asimilar el continuo proceso de crecimiento y perturbación de valores que se está operando en el seno de la sociedad. En esos momentos se trataría de unir la exigencia innata de mantener un grado de independencia cultural en la que el protagonismo de lo nobiliario está presente en todas las esferas de la vida, resaltando los rasgos distintivos de la preeminencia, modificando en cierto modo la ostentación del privilegio, flexibilizando su consideración social, o quizá revistiéndola de un valor mítico y, en fin, elevando a la categoría de rango el criterio de la distinción social situando el protagonismo de lo nobiliario en todas las esferas de la vida que terminará por conformar un universo rico en representaciones, sometido a la evolución social y a los fenómenos que se operaban en ella.

* Deseo expresar mi gratitud a José Luis Colomer quien me sugirió la idea de participar en este seminario. Marc Vitse y Benoît Pellistrandi hicieron posible que esta comunicación viese la luz. A todos ellos, muchas gracias. También a Belén Peláez y a Manuel Amador.

1. El presente artículo forma parte de la investigación que realicé con motivo de mi Memoria de Licenciatura presentada en el Departamento de Historia Moderna de la UCM bajo la dirección de Adolfo Carrasco Martínez: GUILLÉN BERRENDERO, José Antonio, Los valores nobiliarios en la Castilla de Felipe II. Los conceptos de virtud y honor en Juan Benito Guardiola y Francisco Miranda Villafañe, Madrid, 2000.

2. MENESES, Tellez, Lucero de la nobleza de España, Toledo, 1547, f. 20v-21r. 
La sociedad castellana del Antiguo Régimen se presenta polarizada por su propia inercia derivando en la formulación de un lenguaje de los estados diferente para cada grupo, pero que representa una tautología en sí misma, pues intenta dar en todo momento una respuesta que queda a medio camino entre lo intelectual y lo moral, reduciendo su marco conceptual a una serie de representaciones míticas adaptadas a un conjunto social determinado en el tiempo.

Este trabajo pretende ofrecer una línea de interpretación a uno de estos modelos discursivos, los tratados nobiliarios, y a la necesidad de explicación de los mismos como marco referencial de la cultura e ideología nobiliaria y resaltar su operatividad como instrumentos de comprensión del modo de actuar nobiliario. Para ello partiremos de una consideración general de los textos que forzosamente será diacrónica, si bien comenzaremos en 1591 con el texto de Juan Benito Guardiola. Intentaremos ofrecer las pautas generales que caracterizan el género mediante la explicación de una serie de conceptos claves dentro de ideario nobiliario. Posteriormente, analizando las diferentes materias, intentaremos explicar el Tratado de Juan Benito Guardiola como manifestación del modo de vida noble en la España del Siglo de Oro. Nuestro análisis partirá de la consideración general del mismo como un "Espejo de nobles", en el que tendrán cabida la explicación de los modelos nobiliarios de integración social y la justificación de su posición en un entramado de relaciones sociales marcadamente teleológicas.

\section{El valor de la distinción. La conducta noble y su reflejo librario.}

En 1530 escribía Luis de Ávila, médico de Carlos V, un texto titulado Vanquete de nobles caballeros e modo de vivir desde que se levantan hasta que se acuestan. En él se enseña el recto camino y los adecuados hábitos de conducta cotidiana que deben rodear la vida del noble a fin de preservarlo de las "pestilencias" que existen en el mundo. El criterio básico de la vida de los

"nobles caballeros" se situaba para este autor en la mesa, elemento recurrente en la distinción de los estados.

Junto a la conducta cotidiana y alimenticia, Sapientia y Fortitudo aparecen convertidas en elementos esenciales dentro de la ontología nobiliaria, en la que encontramos los elementos básicos para la construcción de la identidad ética del grupo. El Ethos nobiliario se basa en un conjunto de símbolos expresados en un lenguaje comprometido con la sociedad que lo recibe atendiendo a las esencias propias del emisor. Emisor y receptor quedan claramente diferenciados mediante la codificación de un lenguaje reconocible y cargado de manifestaciones positivas de la fuerza del grupo. Lo nobiliario adquiere la dimensión de lo trascendental, del triunfo social como signo de la identidad del grupo. Los textos recogen de forma abierta la 
representación intelectual de las realidades sociales, políticas, culturales y económicas de la nobleza.

¿Qué significa la nobleza y su ética? Una posible respuesta la encontramos en la multitud de estrategias y modelos de integración nobiliaria. Una manifestación de los mimos aparece reflejada en los tratados nobiliarios y en la amplia gama de textos referidos a la jerarquización del grupo. Son manifestaciones de una disciplina social encaminada a la gloria individual y encardinada en un complejo proceso sociopolítico a medio camino entre la imagen real de una sociedad que se observa a sí misma y el artificio ritual de una doctrina rica en significados alegóricos pero que permanece anclada en un ideario atemporal.

Éticamente dibujada, la nobleza aparece revestida de un tamiz voluntarista de rasgos distintivos que la insertan dentro de un espacio cultural propio y elaborado a partir de los intelectuales. De origen clásico, el discurso referido a la conducta nobiliaria recorre un sendero marcado por la asimilación de una serie de valores innatos a la esencia de su estado y que, bien por condicionantes biológico/místicos o por circunstancias vitales como la educación de los nobles, presentan un prototipo humano rico en matices.

"El ser los hombres en la niñez y juventud liberales y amigos de repartir y dar de lo que tienen esles muy natural; la causa desto dize Aristóteles que es el calor natural de que ellos tienen abundancia."."

La educación del noble no debe quedar reducida a un simple aparato ideológico de carácter político, aspectos morales, religiosos, éticos y culturales marcan desde los inicios los rasgos esenciales de lo nobiliario. Una cultura letrada debía ser un complemento más para el perfecto caballero, nunca se discutirá la primacía de armas y letras en la educación del noble, el debate se inscribe dentro de una polémica más elevada, superando el cerrado mundo creado por los intelectuales en torno a las letras como profesión. La cuestión para los nobles no se reducirá al conocimiento intelectual, se trata más bien de un factor de profesionalización dentro de su función política en la sociedad. Esta idea la expone entre otros, Francisco Miranda Villafañe en sus Diálogos de la Phantástica Philosophia, impresos en Salamanca en $1582^{5}$, donde ahonda en el tradicional debate armas-letras, resaltando que la pugna se reduce a diferenciar los espacios de poder reservados a la pluma y a la espada.

La nobleza se convertirá en un grupo creador y consumidor de cultura libraria, bien con un afán coleccionista o manteniendo su tradicional y, en ocasiones,

3. CARRASCO MARTÍNEZ, Adolfo, Sangre, honor y privilegio. La nobleza española bajo los Austrias. Barcelona, 2000, p.12

4. LÓPEZ MONTOYA, Pedro, Libro de la buena enseñança de los nobles: en que se dan muy importantes avisos a los padres para criar y enseñar bien sus hijos, Madrid, 1595, f. 68v.

5. MIRANDA VILLAFAÑE, Francisco, Diálogos de la Phantastica Philosophía. Salamanca, 1582, f. 93r-107v. 
tópico distanciamiento. Lo innegable es la estrecha vinculación entre el grupo y los libros, representación de un deseo cultural y de una expresión determinada en unas formas de inserción social, de un dominio sobre todas las facetas de la sociabilidad, reflejadas como una manifestación más de su identidad y que podemos ejemplificar en el dualismo de armería/librería presente en la mayor parte de las grandes casas nobles castellanas.

Elaboración intelectual enmarcada dentro de un diálogo rico en significantes, la nobleza contiene en su esencia una serie de conceptos que a modo de nodos ofrecen una visión idealizada basada en la construcción de una teodicea social heredada y construida desde el mundo clásico, siendo sus elementos estructurales las figuras de Platón y Aristóteles.

El principio básico de la misma proviene de la existencia de un grupo que posee un conjunto de privilegios que le separan del resto mediante una serie de normas legales o consuetudinarias, expresados en una cultura. La desigualdad está amparada en la formulación de un discurso legitimador y explicativo de la situación de un grupo que domina al resto, ordenándose alrededor de un concepto como el honor, y que desde temprana edad es identificado con la nobleza derivando hacia una interpolación entre autores clásicos y cristianos que permitirán la combinación de diversos factores, así por ejemplo se aludirá insistentemente por parte de varios autores al tópico clásico del templo de la doble puerta como imagen mental de la verdadera significación de la nobleza:

"antiguamente hicieron [los romanos] otro templo a la virtud, y estaba frontero de otro que llamaban de la honra, con sola una puerta para dar a entender que a la verdadera honra no ay mas puerta que la virtud."

Aparte de la clásica trilogía de términos vinculados y justificadores de la posición política de la nobleza, función, linaje y riqueza, otros conceptos adquieren una dimensión capital al referirse a la ética y moral nobiliaria. Términos como liberalidad, magnanimidad, gloria o fama nos refieren realidades complementarias que ayudan a este proceso legitimador. Se trata de conceptos sistémicos referidos a un lenguaje social secuestrado por la nobleza para establecer en torno a ella un capital simbólico singular y configurado sobre el dualismo virtud/honor.

Lenguaje nobiliario intenta reincidir en una argumentación aristocrática del tenor de vida. Sí un autor como Gregorio López Madera escribía en 1597 sobre la importancia de la nobleza en la conformación de la república, el motivo debemos buscarlo en la consideración general por parte de la sociedad de lo nobiliario como su cabeza política y cultural y sus valores como elementos sustantivos del lenguaje social.

6. MORA, Juan de, Discursos morales. Madrid, 1589,f. 95r

7. LÓPEZ MADERA, Gregorio, Excelencias de la Monarchia y Reyno de España, Valladolid, 1597, p.31. 
Lo heterogéneo de la sociedad castellana del Siglo de Oro aparece homogeneizado en la plasmación de un discurso nobiliario referido a la identificación de la nobleza con la idea de bien, siguiendo la máxima aristotélica, pese a que autores como Fernán Pérez de Oliva recurriesen a exponer los pecados de todos los grupos sociales:

"así que todos estos y los demás estados de los hombres no son sino diversos modos de pensar, no ningún caso tienen seguridad en alguno dellos, porque fortuna a todos confunde y los rebuelve con vanas esperanças y vanos semblantes de honras y riquezas.."

Partiendo de un eje argumental que identifica y sitúa a un mismo nivel explicativo a la virtud, la nobleza y el honor, el modo de conducta nobiliario se basa en justificar la génesis de la desigualdad social y la evolución del orden terreno como representación del celestial. La nobleza es hija de la virtud, y el reconocimiento social de la misma se inserta dentro del concepto de honor. El estamento noble posee un honor propio, un concepto con un amplio campo semántico reflejado en una polisemia de realidades políticas concretas que sirven como horizonte vital a todos los individuos, y que provocará la aparición de un amplio debate intelectual sobre la realidad social de los honrados y no honrados.

La constante apelación por parte de los tratadistas y moralistas a centrar la génesis nobiliaria en el acertado ejercicio de la virtud confirma la existencia de un sentimiento dilatante de la esencia nobiliaria expresado mediante un cúmulo ideológico que convierte valores sociales presentes en valores propios gracias a la flexibilidad que los mismos ofrecen a la hora de su interpretación y la incapacidad por parte del resto del tejido social de ofrecer otros modelos discursivos propios fuera del tutelaje de la iglesia.

Como decíamos, existen una serie de conceptos referidos al modo de actuar de los nobles que sirven para focalizar la realidad nobiliaria dentro de una dialéctica que trata de manifestar las esencias distintivas mediante la sutil eliminación de aquellos elementos que perturben la identidad social de la nobleza. La explicación de la nobleza tiene un poso intelectual clásico del que no pueden escapar los autores que sitúan lo nobiliario dentro del amplio repertorio de virtudes morales, sustantivando aquellas que mejor manifiestan la superioridad del grupo, desarrollando de esta forma un discurso subjetivo pero con una amplia operatividad social como refleja la compleja realidad administrativa de las ejecutorias de hidalguía o las informaciones de nobleza de las Órdenes militares.

La verdadera nobleza se encuentra en manifestar la magnanimidad, al unirse en el concepto las cualidades de la nobleza (virtud y honor) con las de la

8. PÉREZ DE OLIVA, Fernan, Diálogo de la dignidad de hombre, Madrid, 1995 (1 ${ }^{a}$ ed. Alcalá de Henares, 1546), p.132-133.

9. El tema del honor y los moralistas ha sido tratado por CHACHAUDIS, Claude, Honneur morale et société dans I'Espagne de Philippe II, París, 1984. 
riqueza conformando un entramado intelectual que encuentra su expresión en una realidad social.

"La Magnanimidad es aquella virtud que consiste en una noble moderación de las pasiones, dándose sólo en aquellos que, conociéndose dignos de ser honrados por los hombres juiciosos." ${ }^{10}$

Esta virtud propiamente nobiliaria tiene una representación iconográfica propia, aunque derivada de la tradición aristotélica que caracteriza al hombre magnánimo ${ }^{11}$. Es representada por los autores de la literatura emblemática e iconográfica siempre de una forma muy similar:

"Mujer hermosa de frente despejada y regular, nariz prominente, que va vestida de oro, llevando la corona imperial en la cabeza, ha de pintarse sentada encima de un León, sujetando un cetro con la diestra y una cornucopia con la siniestra, cayendo de esta ultima además unas monedas de oro." ${ }^{12}$

Si la Magnanimidad está por encima de las demás virtudes propias de la función militar de la nobleza (valor, prudencia, fortaleza, templanza...) es porque resulta ser un compendio de todas ellas, un conjunto cultural propio que es reivindicado por los intelectuales. Manteniendo con respecto a los acontecimientos una distancia suficiente, en estos términos la define Cairasco:

"La Magnanimidad, cuya grandeza,

cuyo valor y alteza es tan subida,

que no hay en esta vida otra mas alta

una mínima falta la disgusta,

como a quien solo gusta de proezas" ${ }^{13}$

Fidelidad, gloria, fama, fe, religiosidad, riquezas, todas ellas son realidades de la esencia conceptual nobiliaria. Conceptos explicados en un conjunto de representaciones escritas y de actuaciones políticas que son sujeto y predicado de una sociedad castellana que experimenta en su seno la evolución política de una Monarquía. También se constituyen en rasgos identificativos de un comportamiento tomado por la sociedad como modélico y que se articula en la literatura nobiliaria.

\section{Tratadística nobiliaria: Lenguaje y legitimación del comportamiento noble.}

Al igual que los textos específicos sobre manejo de las armas, educación de príncipes, etc., los tratados de nobleza representan en sí mismos un manual de

10. RIPA, Cesare Iconología, Madrid, 1986, 35.

11. BARNES, Jonathan (Ed.), The english companion to Aristles, Cambridge, 1995

12. Ibidem.

13. CAIRASCO, Bartolome, Definiciones poéticas, morales y cristianas, ed. de BAE, Madrid, $1951,455$. 
comportamiento, un recordatorio de actitudes que no debe olvidar el noble y el aspirante al privilegio. La respuesta a esta cuestión plantea, ya lo señaló Chevalier $^{14}$, la necesidad de tener en cuenta una serie de factores fundamentales que son de índole social, económica y cultural. Considerando la presencia de estos rasgos, resolveremos la finalidad de este género de obras, y podremos calibrar mejor su peso dentro de la sociedad.

Algunos historiadores españoles han restado importancia al hecho de la existencia de los tratados y de toda la literatura colateral que gira en torno a los valores nobiliarios aunque la realidad parece decirnos algo aparentemente distinto. Reconociendo la existencia en dichos libros de un universo mitificador de la naturaleza de la nobleza no renunciamos a admitir el valor intrínseco de los mismos en un planteamiento que va más allá de lo aparente, y es reflejo de la preocupación por admitir la superioridad e identidad sociopolítica de un grupo sobre el resto de la sociedad y la necesidad de elaborar un contexto intelectual próximo ${ }^{15}$ y común para todo el orbe mediterráneo occidental, sin que por ello resulten de inferior categoría a otros ideológicamente. En todo caso admitiendo la escasa originalidad de sus planteamientos, debemos asumir que la función de la tratadística al uso, no es un medio de transformación de la realidad nobiliaria. Encarnan un punto cardinal en la elaboración y construcción de un espacio que se expresa mediante una serie de valores culturales y de modelos de sociabilidad.

La tratadística representa, tanto en su vertiente jurídica como en la moral, un factor clave de articulación de un discurso de raíz biológica basado en la teoría de la transmisión de ciertos valores mediante la sangre y que aparece expresado en dichos términos. La nobleza es un modelo cultural global y aparece colocada por encima de las personas, convirtiéndose de este modo en una entidad metafísica, posibilitando que los elementos coyunturales sólo afecten a los individuos, nunca a la idea ni al concepto que representan. De este modo la representación pública fundamental de la nobleza, el linaje, encuentra su modo de expresión mediante un código conducente a que no se cuestiones su ontología, expresada en el clásico argumento teorético sobre el origen de su nobleza, la matización aparece cuando un miembro del mismo no se enmarca dentro del modelo teórico de representaciones simbólicas, políticas y sociales.

Aquellos que han conseguido acceder al privilegio mediante el ejercicio de las diversas estrategias sociopolíticas, representan el nivel cardinal dentro de la

14. CHEVALIER, Mlichelle, Lecturas y lectores en la España del siglo XVI y XVII. Madrid, 1976, 13.

15. El profesor Carrasco admite la existencia de esta comunidad de intereses en torno a la elaboración de un discurso que explique el significado de la nobleza. En este sentido parece acertado concluir en la necesidad de acercarnos a ese universo cultural a fin de comprender los elementos de juicio en torno a los cuales los autores del siglo XVI asimilan los cambios que se están produciendo. Ver CARRASCO MARTíNEZ, Adolfo, "Herencia y virtud....", pp.231 y ss. 
asimilación de una situación. Son admitidos dentro de un entramado de relaciones con el nivel superior, estableciendo, en un escalón aparentemente inferior, las relaciones adecuadas para perpetuar su posición sin menoscabo de las demás. En esta situación cobran importancia las representaciones simbólicas de su posición, expresadas todas ellas en la tratadística nobiliaria, en los repertorios genealógicos y otros tipos textuales. Esencialmente representan la constatación de un rasgo de diferenciación evidente reafirmado en un elaborado conjunto de actos positivos públicos insertos en el lenguaje de la sociedad civil.

Tres órdenes de actuación que desde la Edad Media se repiten de manera indefectible hasta adoptar una tipología literaria en sí misma tanto en impresos como en manuscritos. Todos presentan una coincidencia formal e incluso existe una idéntica visión conceptual, o por lo menos ésta es más perceptible en los autores de la primera mitad del siglo XVI, siglo que representa un factor de continuidad con la tratadística medieval, hasta finales del reinado de Felipe II, momento en el que se va a experimentar una cierta renovación en el fondo y que tendrá su punto culminante en el reinado de Felipe III con la publicación, en 1621, del libro de Bernabé Moreno de Vargas Discursos de la nobleza de España, todo un hito en la tratadística del siglo XVII, donde se realiza una apología de la nobleza de mérito y de la figura del rey como otorgador de la merced.

A lo largo del siglo XV, como ha indicado Adeline Rucquoi ${ }^{16}$, se desarrolla en Castilla una literatura nobiliaria dirigida a magnificar la figura del rey como detentador de la gracia y fundamentalmente con la llegada al trono de los Reyes Católicos, se va a producir una revitalización de los libros relacionados con la nobleza, provocando este hecho un giro en la perpetuación de los valores caballerescos, que ahora empiezan a ser patrimonializados por la nobleza ${ }^{17}$. Así Mosén Diego de Valera en su Espejo de la Verdadera nobleza, que dedico al príncipe Juan, evidencia esta transformación y coloca a los reyes como centro de la concesión de la nobleza al considerarla como "una calidad dada por el príncipe, por la cual alguno paresce ser más apto allende los otros onestos plebeios $^{\prime 18}$.

Los mecanismos de recompensa del poder del rey aparecen representados en la tratadística nobiliaria como una prueba consustancial al hecho mismo de la existencia de ambos poderes. El rey debe recompensar los servicios y los receptores de la gracia exigen dicha actitud por parte del monarca, que no es considerada una imposición, sino, más bien, la aceptación de una situación de facto y una contraprestación. Esto resulta irrefutable, pues los defensores de la

16. RUCQUOI, Adeline, <<Etre noble en Espagne auz siècle XIV.XVI >> en OEXLE, Gerhard y O. W. PARAVICINI, eds., Nobilitas, Gottinegen, 1997, pp. 273-298.

17. KEEN, Maurice, La Caballería. Barcelona, 1986, pp. 86.

18. VALERA, Mosen Diego, Espejo de la Verdadera nobleza, BAE, 92. 
transmisión de ciertos valores por la sangre lo que vienen a indicar, de manera sutil si se quiere, es la obligación de ser recompensados por tener sangre noble y, como esta particularidad se transmitirá a sus descendientes, que deben permanecer en la misma situación. Discurso intelectual en el que la sangre convierte al individuo en merecedor de una recompensa que determina que los nobles se conviertan per se en mejores, negando la posibilidad a otros de pertenecer a un sector de la sociedad que comparte parte del privilegio atribuido a la sangre, y a una serie de condicionantes biológicos, representando este hecho un condicionamiento esencial dentro de la actitud nobiliaria en cuanto a sus estrategias internas y en función de la sociedad.

La nobleza es un valor político en si misma adornada por obra y gracia de otro poder con una serie de concomitancias que operan en todos los sectores. Ya hemos comprobado los esfuerzos que realizan los intelectuales para definir virtud y honor, y también se ha constatado el doble lenguaje empleado en este discurso consistente en resaltar lo aparente para engrandecer y mitificar lo real.

La tratadística del siglo XVI, e incluso la del XVII y la del XVIII ${ }^{19}$, manifiesta una clara adaptación del discurso, poniendo en evidencia que "por lo que se refiere a las acciones humanas, las cosas son lo que las gentes que actúan piensan que $s^{\prime \prime n^{20}}$. El pensamiento nobiliario del Siglo de Oro esboza para el caso castellano la realidad del poder social, cultural, ideológico y político del grupo. Es esta literatura tradicional la que mantiene la idea de una nobleza política como parte del orden divino preestablecido ${ }^{21}$.

Esta corriente no se centra únicamente en Castilla, afectará a otras regiones europeas donde el peso de lo nobiliario aparece determinado por su puesto en esferas de poder cada vez más matizadas. Así Giancarlo Angelozzi ${ }^{22}$ dibuja un panorama sobre la literatura nobiliaria de Bolonia, manifestando la preocupación de los autores italianos por definir la esencia de la nobleza y de los valores propios de la misma, estableciendo, al igual que ocurre en Castilla que hay una comunidad universal de valores nobiliarios representados en una literatura

19. MORALES MOYA, Antonio, Poder económico y poder político de la nobleza, La nobleza en el siglo XVIII, Madrid, 1986.

20. IGLESIAS, María del CArmen, $<<$ Los Hombres detrás de las ideas. Una reflexión epistemológica sobre la historia de las ideas políticas $>>$, en IGLESIAS, María del Carmen, Coorda., Homenaje a Luis Díez del Corral. Madrid, 1997, p. 83.

21. Domínguez Ortiz sitúa en esta órbita a Tellez Meneses, Sáez de Varrón, pero deberíamos incluir a Guardiola, Camos Requesens, Jiménez de Urrea, al propio Miranda Villafañe e incluso a autores italianos como Posevinno, Betti, Baldi, Muzio Fausto de Longiano, Nenna, autores que desde una órbita aristotélica apoyan la primacía del cuerpo nobiliario, reduciendo su trascendencia al campo del mérito personal representando sin embargo los valores universales de la nobilitas como recoge. AGUZZI BARBAGLI, Daniello, Op. cit.

22. ANGELOZZI, GIANCARLO, "La trattatistica su nobilta' ed onore a Bologna nei secoli XVI e XVII", en Revista de studi di storia e patria per la provincie di Romagna. XXV-XXVI (197475) Bolonia, 1976, pp. 188-264. 
ensalzadora de la condición de noble. Sin abandonar la península italiana, Donati $^{23}$ ha manifestado como en la segunda mitad del siglo XVI va a operarse de la pluma de los intelectuales una reformulación de los topoi nobiliarios que desde 1550 tenderán a la formulación y definición de un nuevo individuo noble que eclosionará en un enfrentamiento entre la doctrina del gentilhombre y la figura del príncipe absoluto, sin olvidar en el caso italiano que el concepto de ciudadano/no ciudadano, tiende a desarrollar una polarización social semejante a la que en Castilla encontramos con la dualidad, noble/pechero.

En Francia también encontramos muestras de esta literatura. Diego Venturino $^{24}$ ha resumido los trabajos relacionados con la nobleza que algunos autores como Bitton, Schalk y Devyver y Jouanna mantienen acerca de la nobleza francesa. Ésta, al igual que ocurre en la mayor parte de los estados europeos se encuentra asentada sobre un gran número de situaciones que privilegian su condición y aparece en los tratados al uso resaltándose los valores de su clase, representándola como un grupo profundamente heterogéneo y con intereses políticos aparentemente enfrentados, pero que comparten con el resto de noblezas europeas una homogeneización de valores que llevan, como indicó Devyver ${ }^{25}$ a la elaboración de un cierto sentimiento de racismo nobiliario. Un sincretismo $^{26}$ de conceptos que se unen a la idea de la sangre noble, ensalzando a la categoría de mito la idea de vivir noblemente, encubriéndola de un cuerpo místico que refuerza su posición política mediante la posterior elaboración de una serie de modos de integración social, la estructuración de su discurso de legitimación y la operatividad de determinados conceptos que cumplían funciones de integración y de segregación. Ciertamente como ha afirmado Adolfo Carrasco, en torno a la nobleza se elaboran una serie de conceptos más o menos operativos y con una difusión más real que aparente que afectaba a "los modos de organización del estamento y las relaciones entre los distintos grupos que lo componían [...] en definitiva cuestiones referidas al lenguaje y a la cultura nobiliarios $^{\prime 27}$

Estos valores operativos son los que desde la literatura nobiliaria centran su discurso en una serie de puntos en los que los autores muestran un consenso absolutamente inflexible y sobre los que nos centraremos a continuación: a. Definición de la nobleza. b. Fuente de nobleza. c. Jerarquización nobiliaria. d. Modelos culturales de actuación en la sociedad. e. Exclusivismo nobiliario

23. DONATI, CLAUDIO, L iidea di nobiltà in Italia, Secoli XIV-XVIII. Roma, 1995, pp. 94-185.

24. VENTURINO, DIEGO, "L`ideologia nobiliare nella Francia di antico regime", en Studi storici, 29/1, 1988, pp. 61-101.

25. DEVYVER, JEAN, La sang epure, París, 1986.

26. Queremos indicar con la palabra sincretismo, una constante mezcla de valores propios y otros adquiridos, resultado de lo cual aparece un prototipo nobiliario especial.

27. CARRASCO MARTíNEZ, ADOLFO, "Las noblezas de los reinos hispánicos. Modos de integración y conflictos en la segunda mitad del siglo XVI", en E. Belenguer Cebría Coord., Felipe Il y el Mediterráneo, vol. II, Barcelona, 1998, p. 18. 
basado en la superioridad de sus valores. f. Transmisión de valores por vía biológica. g. Títulos nobiliarios.

\section{Definición de nobleza.}

De influencia marcadamente aristotélica, la definición de nobleza gira en torno a dos ideas básicas: la virtud y el honor. En ambos parámetros se desenvuelve la doctrina reflejada por los nobilistas y por los autores políticos del Siglo de Oro, que cuando se refieren a la nobleza enmarcan su definición en idénticas coordenadas conceptuales, que chocarán con las limitaciones propias del lenguaje a la hora de elaborar un discurso identificativo de la materia, pero que saldan la contienda con la utilización a veces indiscriminada de conceptos propios de la casta noble, generando como ya hemos visto y han indicado

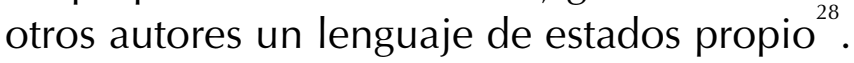

La tipología nobiliaria, cuántos tipos de nobleza existen y cuál de ellas es la más importante será otro foco de atención de los nobilistas. En este caso se alude a la autoridad de Baldo, Otarola, Tiraqueau y otros autores jurídicos. La definición de nobleza establece los mecanismos fundamentales para conformar el estamento, y a su vez exhibe de manera evidente los cauces adecuados para cerrarlo a otros poderes vinculando su existencia a una serie de símbolos propios del estado noble.

\section{La fuente de la nobleza.}

Sí la fuente de la nobleza es en términos absolutos la virtud, el reconocimiento lo confiere el rey a modo de honores ${ }^{29}$ quedando ineludiblemente unidos al concepto de nobleza formando un todo homogéneo asentado en la doctrina religiosa y una práctica política. Como es lógico pensar este asunto despierta la mayor parte de los debates, pues es el factor clave para justificar la situación de preeminencia aludiendo a la transmisión de los valores aristocráticos por la sangre o la certificación de los mismos por la mano del rey. Contienda literaria y social que enmascara un debate más profundo que se opera en el seno de la sociedad sobre quién debe ocupar el poder.

28. Veáse, entre otros, THOMPSON, I.I.A, y CORFIELD, PENELOPE J, dirs., Language, History and Class, Londres, 1991; la obra colectiva VV.AA, Hidalgos \& Hidalguía dans I Espagne des XVle-XVIle siècles, Thèories, practiques et rèpresentations. París, 1989.

29. Los autores de tratados jurídicos sobre la nobleza son los que en el siglo XIV y XVI asientan las bases de esta doctrina, Sasoferrato, Tiraqueau, Baldo, reforzando con ello la definición de nobleza como parte esencial de la sociedad. 


\section{Jerarquización nobiliaria.}

En un tercer escalón encontramos la constatación de los diferentes grados dentro de la jerarquía nobiliaria. La composición de la nobleza no resulta en ningún momento arbitraria, obedece según la mayor parte de los autores a un factor de legitimación del poder, que distribuye la gracia en diferentes estratos según su valía apoyándose en textos jurídicos de una parte y en valores derivados de la costumbre de otra. En otros casos son condicionamientos morales los que marcan la diferencia. Coetáneos como Diego de Hermosilla ${ }^{30}$ ofrecen en este sentido una evidencia de cómo hay diferentes tipos de hidalgos en función de su predisposición de ánimo. La tradicional división de la nobleza ${ }^{31}$ arranca de los tratados bajomedievales, presentando en algunos casos novedades que son la lógica consecuencia de la nueva dinámica social. De dicha estructura nobiliaria se origina también un complicado conjunto de sustantivos conducentes a definir las diferentes categorías que desde los escuderos, infanzones, hidalgos hasta los títulados y grandes, todos los tratadistas intentan definir y que generalmente lleva a una confusión conceptual. En cualquier caso los tratados reflejan una realidad existente en la sociedad que aparece evidenciada en la preocupación por una ejecutoria de hidalguía que permita adscribirse dentro de cualquiera de los diferentes grupos de hidalgos reconocidos por las leyes.

\section{Aspectos culturales de la nobleza.}

Otro asunto fundamental dentro de la elaboración del discurso nobiliario lo representa la necesidad de dejar constancia escrita de los valores culturales de la misma. Punto de consenso entre todos lo autores que insisten en la necesidad de educar a los nobles en la adscripción a una serie de valores propios y de unos comportamientos particulares que los diferencien y otorguen su posición en el seno de la sociedad. En este sentido existe una literatura que sin llegar a la categoría de tratado representa un elemento discursivo igualmente importante en el habitus nobiliario. Nos estamos refiriendo a las instrucciones que se dejan para los descendientes de las familias nobles, de las que serían un buen ejemplo las que dejó Juan de Vega a su hijo en $1592^{32}$.

En cualquier caso, la preocupación por manifestar la necesidad de transmitir una serie de valores se refleja en la existencia de una literatura encaminada a educar a los jóvenes nobles en todos los aspectos necesarios para su posterior

30. HERMOSILLA, DIEGO DE, Diálogo de los pajes de Palacio, 1916 (según el manuscrito de 1573).

31. Domínguez Ortiz ha realizado un resumen de las diferentes clasificaciones nobiliarias ofrecidas por los autores a lo largo del siglo XVI y XVII. Ver DOMíNGUEZ ORTIZ, ANTONIO, La sociedad española en el siglo XVII. Granada, 1992. Vol 2, p. 11.

32. BOUZA, FERNANDO, Imagen, poder y propaganda, Madrid, 1999, pp. 219-234. 
ubicación en la sociedad. Destaca en este caso el trabajo llevado a cabo por Nieves Baranda ${ }^{33}$ que recoge buena parte de los textos encaminados a esta ubicación, y que tendrían su epígono en los libros de educación de príncipes que tanta proliferación alcanzaron en los siglos modernos. Nos encontramos ante autores que irían desde el propio Castiglione hasta Gracían, reflejando en sus obras un gusto especial por el nuevo cortesano y su educación.

\section{Racismo nobiliario}

El lenguaje utilizado por los nobilistas resulta absolutamente excluyente, otorgando valores inconscientes a términos que tradicionalmente aparecían unidos a realidades socialmente diversas. Comprobamos como de un simple nominalismo de funciones se desprende una idea de superioridad social vinculada a los símbolos propios y a la representación de éstos. El caso de la provincia de Vizcaya ${ }^{34}$, y las situaciones de hidalguía universal existentes en dicha región podrían ser consideradas como un ejemplo en este sentido, véase en ejemplo de Poza y su defensa de la hidalguía vizcaína. Comienzan a ser el germen de un absoluto racismo nobiliario, que no sólo tiene manifestaciones religiosas o étnicas ${ }^{35}$, más bien se trata de cuestiones sociopolíticas, representando como manifestó Claude Chachaudis ${ }^{36}$, un concepto racial asentado en la asumción de valores propios e identificativos en un sentido ético-cultural confiriendo a la idea de nobleza un carácter anfibológico, al representar un concepto biológico y un componente moral. Sangre y virtud aparecen sutilmente manipuladas por los autores y puestas al servicio de un fin político-social concreto. Arlette Jouanna ${ }^{37}$ indicaba para el caso francés cómo se estaba produciendo una génesis de la idea de raza y la consecuencia del esfuerzo intelectual de ofrecer un sentido al nuevo orden jerárquico. En Castilla, los teóricos del orden social también tratarán de explicar la jerarquización de la nobleza en función de líneas semejantes, atribuyendo al honor la significación de ser el elemento esencial de las diferentes éticas que convivían en la sociedad. En este sentido los tratados de nobleza vienen ofreciendo un mapa conceptual amplio sobre este particular. Mexia, declarado antibartoliano, destacará, en los últimos años del siglo XV, de forma evidente la singularidad de la nobleza y de sus valores: sangre, honor, riquezas... En el discurso mexianista, si se percibe un poso de exclusivismo nobiliario, una no disimulada toma de postura hacia la superioridad

33. BARANDA, NIEVES, "Escritos para la educación de nobles en los siglos XVI y XVII", en Bulletin Hispanique, 97. Burdeos, 1995, pp.157-171.

34. AZURMENDI, MIKEL, Y se limpie aquella tierra. Barcelona, 2000.

35. Véase la obra de MECHOULAN, HENRY Le sang de l'aautre ou l'honneur de Dieu, Indiens, juisf et morisques au Siècle d’or París, 1979.

36. CHACHAUDIS, CLAUDE Op, cit. p. 163 y ss,

37. JOUANNA, ARLETTE, L'idee de race en France au XVI siècle 
de lo noble sobre lo no-noble Posteriormente, Arce de Otalora vuelve a incidir en esta idea, enmarcando dentro de un cuerpo jurídico la existencia del particularismo cultural nobiliario, que insistimos, no se aborda como una cuestión étnica. La gloria derivada de la sangre se convierte en motor de una raza aristocrática determinada, como ocurría en la Inglaterra de Jacobo I, "exprime avec force la meme idee, les naces nobles sont héréditairement douces pour la vertu".

Esta idea de superioridad viene identificada con la vinculación de la nobleza a un pasado remoto, que en los diferentes estados europeos se establece con los pueblos germánicos que sirven como argumento legitimador para situar a la nobleza en su verdadera dimensión ${ }^{39}$. Los tratados nobiliarios tratarán de perpetuar la identificación de las realidades generando una reformulación agresiva de la nobleza que nosotros entendemos como el alumbramiento de cierta manifestación de un exclusivismo. Como ha indicado Venturino ${ }^{40}$, la clave se encuentra en la definición de las funciones sociales de la nobleza. Esto ocurre en el caso francés, pero ya comprobamos que dicha situación se presenta también en Castilla ${ }^{41}$.

La elaboración del discurso aristocrático debemos relacionarla en último término con un conjunto de ideas heredadas y con un claro matiz elitista. El platonismo y aristotelismo que dejan ver los textos nobiliarios, manejan en todo momento un ideario asentado en la sublimación del Aristos como ser diferente del resto, configurando en el pensamiento occidental un talante aristocrático propio que se deja sentir en el resto de la sociedad a modo de una constante singularización del individuo adornado con la gracia. La virtud, y aquellos más capacitados para comportarse de acuerdo a ella, deberán ser en todo momento los encargados de dirigir a la república.

La idea clásica del héroe, proveniente de la construcción griega, deriva, recorriendo un largo camino, en el que se entrecruzan ideales germánicos, que mitifican el hecho subjetivo de la fuerza motriz de la sangre, haciendo del personaje un conjunto de ideales ${ }^{42}$, convirtiendo la sangre del héroe en un conjunto de virtudes, otorgando a la sangre el valor fundamental dentro de organigrama intelectual de

38. LABATUT, PIERRE, Les noblesses Europeéens du la fin di Xve siècle à la fin du XVIIle siècle París, 1978, p. 72.

39. Ibidem

40. VENTURINO, DIEGO, Op, $\mathrm{cit}_{\mathrm{L}}, 66$.

41. El pensamiento particularista de que ciertas manifestaciones individuales marcan de forma y manera evidente un discurso de exclusión lo representa la idea de Castellano Viejo, dotado de un tipo de honor que no está relacionado con ninguna función de tipo político, pero que encuentra su verdadera dimensión expresada en la incorruptible sangre que le adorna. Así lo han destacado, entre otros, GURIÉRREZ NIETO, JUAN IGNACIO, "Limpieza de sangre y antihidalguismo hacia 1600", en Homenaje a Juan Reglá Campistol, Valencia, 1975, t. II, pp.497-514.

42. WERNER, KARL FERDINAND, Naissance de la Noblesse. París, 1998, 31. 
la nobleza ${ }^{43}$, que establece este mecanismo como defensa ante los intentos de otros grupos por acceder a su cuota de privilegios.

\section{Títulos nobiliarios.}

Sabido resulta que durante el reinado de Felipe II existe una aparente ralentización de la concesión de títulos ${ }^{44}$. En definitiva y como también ha recogido Ignacio Atienza ${ }^{45}$ hay un crecimiento controlado que nada tiene que ver con el posterior del reinado de Felipe IV. Lo que evidencian los apologistas de la nobleza con la representación de todos los títulos es la necesidad de engrandecer a la monarquía gracias a los miembros que en ella conviven, y la consecuencia lógica de esta realidad es su perfecto funcionamiento.

La idea fundamental que vienen a denunciar los libros sobre nobleza es remarcar la existencia de una casta ${ }^{46}$, rica en valores propios y atribuidos por la colectividad, y la necesidad de construir un universo de referentes comprensible por todos y que represente en sí mismo un código ético de comportamiento vinculado a una determinada función social que la nobleza. En relación a ésta doctrina se puden establecer los siguientes puntos esenciales dentro de la tratadística nobiliaria del Siglo de Oro castellano, y que manifiestan abiertamente las formas de sociabilidad de la nobleza:

1 Consideración general de la nobleza como un grupo esencial dentro de la sociedad, evidenciando lo especial de sus funciones.

2 Caracterización moral de la nobleza, identificándola con la idea de BIEN y un conjunto de sinónimos referidos a dicha idea.

3 Conceptualización de la nobleza relacionada con su función social, rescatando para ello un conjunto retórico útil para desarrollar un discurso coherente que difunda entre sus miembros la idea de singularidad social.

4 Desarrollo de una doctrina encaminada a vincular al estamento hacia el desempeño de un poder político derivado del conjunto de privilegios que se le atribuyen.

5 Reinvención y posterior adaptación de un discurso de carácter moral sobre los conceptos de virtud y honor, consiguiendo realizar un completo corpus intelectual sobre lo que dichos conceptos representan, convirtiéndolos en valores propios de la nobleza.

43. DEVYVER, ANDRÉ, Op. cit., p. 186.

44. CARRASCO MARTÍNEZ, ADOLFO, "Las noblezas...", p.18.

45. Ignacio ATIENZA HERNÁNDEZ, IGNACIO, Aristocracia, poder, riqueza en la Edad Moderna, La casa de Osuna, Madrid, 1987, pp. 17-23.

46. GUTIÉRREZ NIETO, JUAN IGNACIO, "La estructura castizo..." p. 526. 
6 Singularización de la condición de noble que se dirige hacia la elaboración de un ideario de carácter racista, y que denominamos racismo nobiliario, basado en la primacía de ciertos valores conscientes e inconscientes sobre otros, y en la asimilación de estos por el resto de la sociedad.

7 Glorificación de la nobleza castellana y de su relación con la corona, generando así un lenguaje de los estados vinculado a una determinada posición jerárquica en el seno del poder.

8 Ensalzamiento de la jerarquía nobiliaria como reflejo de la idea de desigualdad social imperante.

9 Existencia de dos aparentes antinomias en la consideración del origen de la nobleza: el mérito o la sangre. Ambas realidades obedecen a la elaboración de un discurso que en ambos casos ayuda a singularizar la condición de noble. El que desde una irreal igualdad social, consigue la condición de noble, desde ese momento se manifiesta como diferente. Y la vinculación de la nobleza con la idea de la herencia de las cualidades, relaciona de manera evidente este hecho, resultando de la pluma de los intelectuales un consenso, que busca suavizar las aparentes contradicciones surgidas de la desigual distribución de honores.

10 consideración de la nobleza como un valor social y político.

En todo caso estas conclusiones deben quedar relacionadas con cuestiones más concretas propias del periodo histórico, tales como la respuesta postridentina por parte de ciertos intelectuales, el peso cada vez más determinante de la limpieza de sangre y su inserción en las esferas de gobierno. Un elemento sustancial resulta también la evolución del ejercicio de la guerra y la nueva dimensión tanto estratégica como moral que adquiere, para finalmente insertarlos dentro de una consideración de las formas específicas de la política y la administración de los asuntos de gobierno.

\subsection{El Tratado de Nobleza de Juan Benito Guardiola, espejo de nobles.}

Lo dicho hasta ahora nos sirve como elemento introductorio y marco global de lo que representaban los tratados nobiliarios tanto en Castilla como en Europa y para centrar nuestro trabajo en el texto de Juan Benito de Guadiola.

En 1591 vio la luz el texto Tratado de nobleza y de los titulos y ditados que oy dia tienen los varones claros y grandes de España, en la imprenta de la viuda de Alonso Gómez. Juan Benito Guardiola, su autor, era un monje benedictino, del monasterio de San Benito el Real de Sahagún que dedicó parte de su vida a trabajar en la realización de diferentes obras de carácter genealógico. También desarrollo una importante labor como bibliotecario en la casa de don 
Diego Sarmiento de Acuña, futuro conde de Gondomar. Lo que nos interesa resaltar es su labor como tratadista y glosador de la ideología nobiliaria dominante en Castilla en lo últimos años del reinado de Felipe II de la que es testimonio este Tratado junto con una serie de genealogías que él mismo realizó ${ }^{47}$.

El libro del Guardiola exhibe un marcado carácter utilitarista. Un aspecto importante es su dimensión de manual de conducta. Si como hemos comprobado los textos nobiliarios sirven de argumento legitimador de la posición social de la nobleza, Guardiola también aborda una delicada cuestión: ¿se aprende a ser noble? Los valores morales nobiliarios aparecen así enclaustrados entre las cuatro paredes del estamento y sin dejar resquicios a posibles fenómenos de aculturación de otros grupos sociales. La preocupación por "educar" a la aristocracia obedece a una necesidad de perpetuar en las generaciones jóvenes, los valores simbólicos propios a fin de resaltar las singularidades ${ }^{48}$. Hexter en su artículo sobre la educación de la aristocracia inglesa en el Renacimiento $^{49}$, confirma la existencia de un compromiso absoluto a la hora de educar a los individuos en una nueva conceptualización de algunos valores. La Contrarreforma afecta también al hecho de la educación de la élite dirigente ${ }^{50}$, expresando una voluntad de unificación de valores católicos.

Guardiola comparte la idea de que la nobleza es un valor social. Coincide en este sentido con autores como López Madera, Gutiérrez de los Ríos o Urrea. Éstos defienden una nobleza de la virtud y de la sangre, considerando ambos conceptos como innatos a su condición, pero no olvidan que debe existir una preparación adecuada por parte de los jóvenes nobles. Ya en la Edad Media se escriben en Castilla diferentes obras dedicadas a la educación de los príncipes y la nobleza. Mediante la elaboración de instrucciones a los niños nobles se establecen los hábitos de conducta que deben regir su vida de adultos. El tratado representa, en nuestra opinión, un instrumento educativo de la media y baja nobleza que necesita de instrumentos intelectuales propios que confieran su experiencia como grupo aristocrático.

Dentro de la consideración general del tratado como un espejo de nobles, debemos atender a una serie de aspectos en los que Guardiola se fija a la hora de centrar la utilidad del texto y que nos remiten a la necesidad de mostrar y

47. De la multitud de estudios genealógicos realizados por el benedictino debemos hacer mención al conjunto de ellos que se conservan en la BNE, en su sección de manuscritos bajo en nombre de Obras, corresponden a la serie los manuscritos, 2243, 12882, 7340. En la Real Biblioteca el manuscrito II/1677;

48. Uno de los primeros estudios sobre los tratados de educación de las élites lo representa la obra de GALINO CARRILLO, ANTONIO, Los tratados sobre educación de Príncipes, Siglos XVI-XVII. Madrid, 1948.

49. HEXTER, JONATHAN, "The Education of the Aristocracy in the Renaissance" en Reappraisals in History, New views on history and society early modern England. Chicago, 61, pp. 45-70.

50. GARÍN,EUGENIO, La educación en Europa,1400-1600. Barcelona, 1987. 
enseñar de la literatura. De esta forma, el benedictino establece una estructura bipolar intentando asentar las bases de la cultura nobiliaria. Por un lado, la nobleza debe ser espejo de la sociedad y su comportamiento imitado por ésta y, por otro, la nobleza es un valor político. Es en esta segunda vía, donde entroncamos con la consideración del tratado como un programa político de la nobleza.

Identificando cultura como un concepto global que expresa las formas y estructuras en que un grupo se define y relaciona, la obra de Guardiola incide en esta consideración. Habla de una alta cultura, de carácter aristocrático, representada en su texto en una serie de capítulos que manifiestan un ideario individual y social. Concretamente, el autor dibuja un planteamiento global de la nobleza y de sus signos, expresados tanto en realidades inmateriales (la definición de nobleza, las formas de acceso) como en la explicación de las cuestiones reales (la definición de honor, la explicación de la jerarquía nobiliaria, la construcción del lenguaje heráldico de las armas...). Marcadamente platónico, incide en la idea de identificar nobleza y bondad, partiendo del concepto de virtud. Así indica Guardiola que "della solo es merecedor y digno el bueno y virtuoso $^{\prime \prime 1}$ y citando a Platón y a su Ética (capítulo III libro 4), continúa alabando la honra, la virtud y el modo de expresión de un grupo identificado en todo momento con una conducta social selectiva.

"La honra es una dignidad adquirida por la virtud de manera que la virtud es de la essencia de la honra, y entra en su definición como cosa sustancial" ${ }^{52}$

Años más tarde López Montoya en su obra Libro para la educación y enseñanza de los nobles, abordaba la cuestión de enseñar a los jóvenes nobles a ser modelo de la sociedad, pues ellos son los Ilamados a desempeñar las tareas de gobierno de la república, continuando con una tradición más desarrollada en Italia de la educación de los niños nobles:

"Tome por fin, y por título deste libro, la enseñança de los nobles, porque a ellos procura siempre imitar la demas gente [...] porque ha de servir para que los que tienen nobleza de sus mayores la conserven y lleven adelante, y los que no la tienen la adquieran con abrazar y seguir desde niños la virtud." ${ }^{153}$

El elogio de la virtud que realiza el autor nos lleva más lejos de una pura retórica intelectual, su pretensión es ofrecer a la sociedad civil un manual de lo que el comportamiento noble significa y como este modus actuandi debe ser reflejado en la sociedad. La idea no es nueva, ya Pedro Mexía en su Silva de Varia lección resalta la importancia de la virtud como fuente de nobleza y vuelve

51. GUARDIOLA, JUAN BENITO, Tratado, $1 \mathrm{r}$

52. Ibidem.

53. LÓPEZ MONTOYA, PEDRO, Libro de la buena educación y enseñança de los nobles, Madrid, 1595, 3r. 
a identificar los conceptos que deben ser enseñados a los jóvenes caballeros, a los príncipes, como parte integrante de un mismo grupo de personas ${ }^{54}$ y que aparecen representadas en la identificación de una serie de conceptos propios que lejos de quedar indefinidos se vinculan entre sí, formando un eje nodal sobre el comportamiento noble.

Guardiola es buen conocedor de la realidad social de su tiempo, y como tal, mantiene la idea de la legitimidad del deseo de honra, y como éste no es sólo bueno para el hombre como ser individualizado, las repúblicas también gozarán de estos beneficios, pues la nobleza es un bien general del que gozan unos pocos, pero que gracias a esta calidad patrimonializada por un grupo, toda la sociedad resulta premiada. Guardiola enseña a la nobleza que se estime en sí misma y legitima sus principios en el eje virtud-honor.

"y como dize Platón, que la honra es una dignidad adquirida por la virtud, de manera que la virtud es la esencia de la honra y entra en su definición como cosa suya substancial." ${ }^{55}$

Una parte fundamental del discurso guardileño lo representa el apartado dedicado a definir las formas de adquirir nobleza. Se pone el acento en la definición, cuestión capital dentro del debate sobre la nobleza, cifrando la exégesis conceptual en una dimensión ontológica, la virtud y la sangre representan el dualismo relativo a la consideración global de lo nobiliario como entidad metasocial, obteniendo de su combinación la identidad propia del grupo.

\subsection{Nobleza y poder.}

La interpretación de un texto de las características del de Guardiola ofrece la posibilidad de conocer al grupo nobiliario desde múltiples vertientes. Como visión general del mismo ofrecemos una serie de elementos indispensables a la hora de abordar un estudio de la nobleza y de sus modos de interactuar dentro de una sociedad. En primer lugar consideramos el texto como un instrumento de legitimación al servicio de un fin político-social concreto y que la profesora Quintanilla cifra como esencial, ya que "el proceso de legitimación nobiliaria se insertaba por tanto, en el marco de un equilibrio funcional necesario, en el que poder justificar la posición preeminente que le correspondía." ${ }^{56}$ Valorados junto con otra serie de recursos puestos al servicio del estamento, los tratados constituyen un elemento básico dentro de la dinámica propia del cuerpo social de la nobleza, y representan en un sentido más amplio un espacio intelectual propio, reforzado por una amplia gama de fuentes tanto literarias como religiosas y jurídicas

54. VARELA, JUAN, Modos de Educación en la España de la Contrarreforma, Madrid, 1983, 50.

55. GUARDIOLA, JUAN BENITO, Tratado... $1 \mathrm{r}$.

56. QUINTANILLA RASO, MARÍA CONCEPCIÓN, "La nobleza", en NIETO SORIA, JOSÉ MANUEL, dir., Los Orígenes de la Monarquía hispánica, Propaganda y legitimación, Madrid, 1999, 63-77. 
que evidencian un marco conceptual más amplio en relación con la idea de nobleza siendo también una fórmula tradicional de exponer las ideas de forma estructurada. En este sentido resaltaremos los instrumentos retóricos del autor para legitimar a la nobleza y que podemos dividir en: a. Legitimación por el mérito (la virtud como fuente de nobleza y creadora de un espacio intelectual propio). b. Legitimación por la herencia (la vinculación de la nobleza con la sangre). c. Legitimación por la riqueza (el poder económico de la nobleza).

En consonancia directa con su valor instrumental, debemos resaltar el marcado carácter pedagógico, representado en un corpus doctrinal dirigido a identificar los rasgos de inserción que utiliza el estamento en sus niveles jerárquicos más bajos y que sirven como medio de aprendizaje e imitación de los espejos de príncipes siendo un complemento a las tradicionales instrucciones que se realizaban a los jóvenes herederos de los grandes linajes. Existe pues una relación entre la consideración anterior del tratado y su vertiente educativa sirviendo como mecanismo de ubicación y determinación social.

En tercer lugar consideramos la consecuencia directa de los dos aspectos anteriores: la plasmación en el texto de un programa político de actuación e inserción en la sociedad y con respeto a su esencia, intervención política reflejada a modo de formulación de una serie de identidades propias, que definen el valor político del grupo. Una determinación por conocer sus verdaderas fronteras políticas para no sufrir enfrentamientos en su seno, que derivará en una concepción global, que hemos denominado representación de sus valores culturales. Considerada aquí como un corolario de los anteriores, y que también tiene entidad propia, redundando en ciertos aspectos, pero resaltando las estrategias sutiles de inserción dentro de la sociedad mediante la elaboración de mecanismos simbólicos que acaban por desarrollar un panorama que en palabras de Burke ${ }^{57}$ desarrollaría un concepto total de cultura. En este caso lo debemos aplicar a la definición de nobleza y a la interpretación y asimilación que de ellos tiene el conjunto de la sociedad y el grupo noble en particular, determinado a reconocer su verdadero valor simbólico.

Guardiola realiza en su texto, una profunda declaración de principios en el prólogo al lector, indicando su vocación de servicio, no ya a la corona, ni a Dios, pues su interés va más allá de estos poderes, sino a la república. El autor es consciente de la necesidad de que exista un conocimiento que legitime a la nobleza y mantenga la estructura de poder, para ello es esencial que se produzca un conocimiento total de las realidades del estamento privilegiado:

"Fuy siempre tan naturalmente inclinado a los varones nobles y illustres, assi en letras y virtudes, como por la esclarecida antigüedad de sus linajes y familias dignas de memoria que tuve

57. BURKE, PETER, "Historia cultural e historia total", en OLABARRI, IGNACIO y Francisco Javier CASPISTEGUI, FRANCISCO JAVIER, dirs: La nueva historia cultural: la influencia del postestructuraclismo y el auge de la interdisciplinariedad, Madrid, 1996, p.115. 
por bien de querer tomar a cargo empresa de tanto valor, como es escrevir este tratado de nobleza...." ${ }^{58}$

El sistema de legitimación nobiliario que representa Guardiola, tiene como eje un espacio tripartito, relacionando entre sí las líneas de conexión de la sangre y el linaje y vinculando éstos a la riqueza, ilustrando que las riquezas necesitan el apoyo inequívoco de la sangre. De esta forma los intelectuales desarrollan su discurso legitimador, en que el linaje no queda reducido a un referente biológico sin más: su verdadera dimensión es un factor vinculado a aspectos fundamentalmente políticos asociados a dos realidades inmateriales, la virtud y la herencia. El resultado de todo es la elaboración de un concepto de linaje en el que aparecen como realidades inmanentes la virtud y el honor, elementos determinantes que son complementados con las riquezas estableciendo con ello un articulado y homogéneo cuadro de la nobleza en su dimensión material e inmaterial y siendo observada tanto desde una perspectiva émic como étic.

Marcadamente bartoliano en algunos de sus argumentos referidos a la consideración general de la dignidad propia del hombre noble, muestra una paradójica oposición a la circunstancia de otorgar al mérito una prioridad esencial en la composición de la naturaleza nobiliaria. En Guardiola encontramos una inclinación hacia la doctrina encardinada en considerar a la nobleza como una consecuencia lógica de un determinado comportamiento, y la adecuación de esta circunstancia al peso de la sangre, factor éste coincidente con el jurista Arce de Otalora.

En consecuencia planteamos el análisis de la obra desde esta triple argumentación basada en la idealizada concepción del estamento ofrecida por el autor y que se adivina en la definición de nobleza que ofrece, donde se entrecruzan una serie de argumentos morales y teológicos que resultan operativamente válidos:

"Las tales virtudes y grandes hechos no han de ser sin galardon. Y asi las buenas obras de los gentiles que fueron en muchos actos y virtuosas hazañas, aunque no fuessen para alcanzar la bienaventurança, no quedaron sin premio, porque en pago dellas les permitio dios muchas victorias de sus enemigos, y mucha prosperidad temporal; y por tanto estos tales se pudieron llamar con muy justa razón nobles, pues que vemos que alcanzaron titulo y renombre de ser conocidos por causa de su propia virtud, en lo qual consiste la verdadera nobleza." ${ }^{59}$

A modo de una serie de notas (que desarrollaremos más en el texto definitivo) de los que el autor defiende y considera como valores culturales propios de la nobleza debemos señalar el conjunto de lugares comunes dentro de las ideas en torno a la nobleza, que por mor de ser muy repetidas no dejan de insistir en una realidad más amplia, manteniendo en todo momento un discurso coherente sobre lo que la nobleza representa:

58. GUARDIOLA, JUAN BENITO, Tratado. 10.

59. Ibidem, $2 r$. 
1 LA VIRTUD COMO FUENTE DE NOBLEZA. Animando a los miembros del grupo a que mantengan un comportamiento acorde a su condición, legitimándose a sí mismos al mantener un comportamiento amparado en la propia virtud y en la de sus antepasados. En este sentido se inscribe a la nobleza en un sistema completo de virtud sobre el que gira la exégesis intelectual del estamento y de aquellos autores que desde posiciones morales intentan ofrecer una diferente concepción de la virtud nobiliaria.

2 EL HONOR COMO MECANISMO DE COACCIÓN SOCIAL. Se indica como el honor representa en sí mismo un poder político. Despojándolo de su vertiente sexual, teatral si se quiere, Guardiola ofrece un sistema del honor, relacionado con las manifestaciones culturales de la virtud.

3 ELEMENTOS REPRESENTATIVOS DEL PODER. La nobleza asume su función dentro de la sociedad desde la Edad Media. De esta realidad nacen los mecanismos redistributivos generados por la sociedad para que dicho poder sea reconocido. La nobleza aparece como representación del mundo político, estrechamente vinculada al rey. Guardiola indica lo necesario que resulta a la nobleza que muestre su poder político mediante un conjunto de símbolos propios, adquiridos en el ejercicio de su función social, creando un escenario iconográfico propio, con un lenguaje individualizado en cada noble, pero que el benedictino encaja dentro de un mecanismo colectivo de conducta. Este hecho cobra una relevancia fundamental, al estar dirigido a un segmento de la nobleza que necesita adquirir los valores propios del estamento.

4 LA FUERZA DE LA SANGRE FRENTE A LA NECESIDAD DEL MÉRITO. Un elemento fundamental dentro del debate existente en la sociedad castellana es el referido a cuál debe ser la función esencial de la nobleza. Es necesario dejar claro que Guardiola no es un defensor de las letras en los términos del clásico debate entre armas y letras. Él otorga a la espada todo el peso de la representación social, pero, sin embargo, debe conciliar esta injusta desigualdad en el acceso al privilegio, y para ello recurre al mismo argumento que utiliza para explicar la fuente de la nobleza. Si las armas son prueba inequívoca de la nobleza de su poseedor, las letras requieren de un aparente proceso de concesión. Discernir si el sabio es digno de nobleza, este argumento destila un posibilismo radical, al considerar que todo lo útil puede ser digno de nobleza. El sabio es noble en tanto en cuanto es bueno, y por esa bondad de la sabiduría es noble, creando en torno al noble como individualidad un sistema de representaciones inmateriales que nos acercan a lo que indicó Chiara Continissio acerca de la existencia de un sistema de virtud. Qué el benedictino considere que estas manifestaciones son muestras de nobleza, tampoco resulta inocente, son una forma más de constatar la constante elaboración de un discurso justificativo de los valores reales y simbólicos que posee la nobleza, y son utilizados ahora como instrumento educativo de 
incalculable valor, porque como indicaba Brântöme "porter les armes est la marque de la noblesse."

La nobleza encuentra de este modo un medio de expresión propio, comprensible y adecuado a sus necesidades. En él se priman una serie de elementos constitutivos de su naturaleza, explicándolos desde una postura abiertamente nobilista. En primer lugar se indica a la virtud y el honor como valores propios, que determinan la conducta del hombre noble. Un segundo escalón lo forma la consideración general que se hace de la familia noble, expresada como hemos visto en el linaje, y que representaría un aspecto fundamental en la definición del estamento, al representar un elemento de permanencia. ${ }^{61}$ Otro factor dentro de los órganos identificativos de la personalidad nobiliaria lo encontramos en la definición de su estructura jerárquica, finalizando con la argumentación retórica que justifica su preeminencia social: la función. Definiendo a la nobleza desde la importancia que adquieren sus funciones dentro de la sociedad, se determina claramente la necesidad de su existencia, y la importancia de un mundo aristocrático y aristocratizante que día a día va dibujando dicho panorama social $^{62}$.

La hegemonía social y cultural ejercida por la nobleza en los siglos modernos produce una literatura que nos ayuda a comprender una dimensión más de su realidad histórica así como nos facilita una serie de elementos "para comprender la ordenación de las sociedades humanas y para discernir las fuerzas que las hacen evolucionar, importa prestar atención a los fenómenos mentales, cuya intervención es [...] tan determinante como la de los fenómenos económicos y demográficos." ${ }^{163}$ La verdadera trascendencia de la nobleza ha de estudiarse desde diferentes puntos de vista, siendo el que aquí tratamos una manifestación más de un valor individualizado que debe ser adscrito al resto de enfoques para ser capaces de enmarcar al grupo privilegiado en la concepción real por parte de sus coetáneos.

Es necesario conocer los aspectos multiformes de la realidad nobiliaria, para alcanzar un verdadero conocimiento de las variantes culturales y de las diferentes formas de sociabilidad que conforman su ideario y que están recogidas en la amplia gama de textos que se escriben sobre la nobleza. El estudio de la cultura nobiliaria no desdeña en absoluto otros enfoques del grupo, al contrario sirve como contextualización general no ya de un estamento determinado

60. Cit por P. LABATUT, Op, cit., 85.

61. Ibidem. 71.

62. En este sentido se ha intentado ver en la vida aristocrática un patrón de comportamiento propio, que sirvió de referente a los orígenes de la cultura moderna. Véase para el caso francés la obra de DEWALD, JONATHAN, Aristocratic experience and the origins of the modern culture. Oxford, 1993.

63. DUBY,GEORGES “Historia social e ideología de las sociedades", en LE GOFF, JACQUES y NORA, PHILIPE, dirs., Nuevos problemas, Vol. I. Barcelona, 1978, pp.157-158. 
sino de la sociedad del Antiguo Régimen y más concretamente del Siglo de Oro castellano.

\section{Bibliografía}

AGUZZI BARBAGLI, Daniello, $<<$ La difensa de valori etici nelle trattatistica sulla nobilta $>>$ en Rinascimento, 1989, pp. 377-427.

ANGELOZZI, Giancarlo, <<La trattatistica su nobilta' ed onore a Bologna nei secoli XVI e XVII >>, en Revista de studi di storia e patria per la provincie di Romagna. XXV-XXVI (1974-75) Bolonia, 1976, pp. 188-264.

ATIENZA HERNÁNDEZ, Ignacio, Aristocracia, poder, riqueza en la Edad Moderna, La casa de Osuna, Madrid, 1987.

AZURMENDI, Mikel, Y se limpie aquella tierra. Barcelona, 2000.

BARANDA, Nieves, <<Escritos para la educación de nobles en los siglos XVI y XVII>>, en Bulletin Hispanique, 97. Burdeos, 1995, pp.157-171.

BARNES, Jonathan (Ed.), The english companion to Aristles, Cambridge, 1995.

BOUZA, Fernando, Imagen, poder y propaganda, Madrid, 1999.

BURKE, Peter, <<Historia cultural e historia total $>>$, en OLABARRI, IGNACIO y Francisco Javier CASPISTEGUI, Francisco Javier, dirs: La nueva historia cultural: la influencia del postestructuraclismo y el auge de la interdisciplinariedad, Madrid, 1996, pp.115-122.

CAIRASCO, Bartolome, Definiciones poéticas, morales y cristianas, ed. de BAE, Madrid, 1951.

CARRASCO MARTÍNEZ, Adolfo, << Herencia y Virtud. Interpretaciones e imágenes de lo nobiliario en la segunda mitad del siglo $\mathrm{XVI}>>$ en ENCISO RECIO, Luis Miguel, coord., Las Sociedades Ibéricas y el mar a fines del siglo XVI. LA corona de Castilla,. t.IV, Madrid, 1998, pp.231-270,

CARRASCO MARTÍNEZ, Adolfo, <<Las noblezas de los reinos hispánicos. Modos de integración y conflictos en la segunda mitad del siglo $\mathrm{XVI}>>$, en E. Belenguer Cebría, Coord., Felipe Il y el Mediterráneo, vol. II, Barcelona, 1999, pp. 17-60.

CARRASCO MARTÍNEZ, Adolfo, Sangre, honor y privilegio. La nobleza española bajo los Austrias. Barcelona, 2000.

CHACHAUDIS, Claude, Honneur morale et société dans I'Espagne de Philippe II, París, 1984.

CHEVALIER, Mlichelle, Lecturas y lectores en la España del siglo XVI y XVII. Madrid, 1976. 
DEVYVER, Jean, La sang epure, París, 1986.

DEWALD, Jonathan, Aristocratic experience and the origins of the modern culture. Oxford, 1993.

DOMÍNGUEZ ORTIZ, Antonio, La sociedad española en el siglo XVII. Granada, 1992.

DONATI, Claudio, L`idea di nobiltà in Italia, Secoli XIV-XVIII,. Roma, 1995.

DUBY,GEORGES, <<Historia social e ideología de las sociedades $>>$, en LE GOFF, Jacques y NORA, Philippe, dirs., Nuevos problemas, Vol. I. Barcelona, 1978, pp.157-158.

GALINO CARRILLO, Antonio, Los tratados sobre educación de Príncipes, Siglos XVI-XVII. Madrid, 1948.

GARÍN,Eugenio, La educación en Europa,1400-1600. Barcelona, 1987.

GUILLÉN BERRENDERO, José Antonio, Los valores nobiliarios en la Castilla de Felipe II. Los conceptos de virtud y honor en Juan Benito Guardiola y Francisco Miranda Villafañe, Madrid, 2000.Memoria inédita de licenciatura.

GURIÉRREZ NIETO, Juan Ignacio, <<Limpieza de sangre y antihidalguismo hacia 1600>>, en Homenaje a Juan Reglá Campistol, Valencia, 1975, t. II, pp.497-514.

HERMOSILlA, Diego de, Diálogo de los pajes de Palacio, 1916 (según el manuscrito de 1573).

HEXTER, Jonathan, <<The Education of the Aristocracy in the Renaissance $>$ en Reappraisals in History, New views on history and society early modern England. Chicago, 61, pp. 45-70.

IGLESIAS, María del Carmen, <<Los Hombres detrás de las ideas. Una reflexión epistemológica sobre la historia de las ideas políticas $>>$, en IGLESIAS, María del Carmen, Coorda., Homenaje a Luis Díez del Corral. Madrid, 1997.

JOUANNA, Arlette, L'idee de race en France au XVI siècle, París, 1976.

KEEN, Maurice, La Caballería. Barcelona, 1986.

LABATUT, Jean Pierre, Les noblesses Europeéens du la fin di Xve siècle à la fin du XVIIle siècle, París, 1978.

LÓPEZ MADERA, Gregorio, Excelencias de la Monarchia y Reyno de España, Valladolid, 1597.

LÓPEZ MONTOYA, Pedro, Libro de la buena educación y enseñança de los nobles, Madrid, 1595. 
MECHOULAN, Henry, Le sang de l'aautre ou l'honneur de Dieu, Indiens, juisf et morisques au Siècle d’or París, 1979.

MENESES,Tellez, Lucero de la nobleza de España, Toledo, 1547.

MIRANDA VILLAFAÑE, Francisco, Diálogos de la Phantastica Philosophía. Salamanca, 1582.

MORA, Juan de, Discursos morales. Madrid, 1589.

MORALES MOYA, Antonio, Poder económico y poder político de la nobleza, La nobleza en el siglo XVIII, Madrid, 1986.

PÉREZ DE OLIVA, Fernan, Diálogo de la dignidad de hombre, Madrid, 1995 (1aㅗ ed. Alcalá de Henares, 1546

QUINTANILLA RASO, María Concepción, <<La nobleza >>, en NIETO SORIA, José Manuel, dir., Los Orígenes de la Monarquía hispánica, Propaganda y legitimación ${ }_{\llcorner}$Madrid, 1999, 63-77.

RIPA, Cesare Iconología, Madrid, 1986.

RUCQUOI, Adeline, <<Etre noble en Espagne auz siècle XIV.XVI >> en OEXLE, Gerhard y O. W. PARAVICINI, eds., Nobilitas, Gottinegen, 1997, pp. 273298.

THOMPSON, I.I.A, y CORFIELD, PENELOPE J, dirs., Language, History and Class, Londres, 1991.

VALERA, Mosen Diego, Espejo de la Verdadera nobleza, BAE,1956.

VARELA, Juan, Modos de Educación en la España de la Contrarreforma, Madrid, 1983.

VENTURINO, Diego, $<<$ ¿`ideologia nobiliare nella Francia di antico regime >> en Studi storici, 29/1, 1988, pp. 61-101.

VV.AA, Hidalgos \& Hidalguía dans I'Espagne des XVIe-XVIle siècles, Thèories, practiques et rèpresentations. París, 1989.

WERNER, Karl Ferdinand, Naissance de la Noblesse. París, 1998. 